\title{
Differential Protein Quantitation in Mouse Neuronal Cell Lines using Amine- Reactive Isobaric Tagging Reagents with Tandem Mass Spectrometry
}

\author{
Kun Cho ${ }^{\mathrm{a}, \mathrm{b}}$, Gun Wook Park ${ }^{\mathrm{a}, \mathrm{c}}$, Jin Young Kim ${ }^{\mathrm{a}}$, Sang Kwang Lee ${ }^{\mathrm{a}}$, Han Bin $\mathrm{Oh}^{\mathrm{b}}$, and Jong Shin Yoo ${ }^{\mathrm{a}, \mathrm{c} *}$ \\ ${ }^{a}$ Division of Mass Spectrometry Research, Korea Basic Science Institute, Ochang, 863-883, Korea \\ ${ }^{b}$ Department of Chemistry, Sogang University, Shinsu-Dong 120, Seoul 121-742, Korea \\ ${ }^{c}$ Graduate School of Analytical Science and Technology, Chungnam National University, Daejon 305-764, Korea
}

Received November 14, 2010; Revised November 14, 2010; Accepted November 14, 2010

First published on the web December 15, 2010; DOI: 10.5478/MSL.2010.1.1.025

\begin{abstract}
The high-throughput identification and accurate quantification of proteins are essential strategies for exploring cellular functions and processes in quantitative proteomics. Stable isotope tagging is a key technique in quantitative proteomic research, accompanied by automated tandem mass spectrometry. For the differential proteome analysis of mouse neuronal cell lines, we used a multiplexed isobaric tagging method, in which a four-plex set of amine-reactive isobaric tags are available for peptide derivatization. Using the four-plex set of isobaric tag for relative and absolute quantitation (iTRAQ) reagents, we-analyzed the differential proteome in several stroke time pathways $(0,4$, and $8 \mathrm{~h})$ after the mouse neuronal cells have been stressed using a glutamate oxidant. In order to obtain a list of the differentially expressed proteins, we selected those proteins which had apparently changed significantly during the stress test. With $95 \%$ of the peptides showing only a small variation in quantity before and after the test, we obtained a list of eight up-regulated and four down-regulated proteins for the stroke time pathways. To validate the iTRAQ approach, we studied the use of oxidant stresses for mouse neuronal cell samples that have shown differential proteome in several stroke time pathways $(0,4$, and $8 \mathrm{~h})$. Results suggest that histone $\mathrm{H} 1 \mathrm{might}$ be the key protein in the oxidative injury caused by glutamate-induced cytotoxicity in HT22 cells.
\end{abstract}

Key words: iTRAQ, MALDI-MS/MS, Proteomics, Mouse neuronal cells

\section{Introduction}

The development of various approaches for the measurement of the relative expression of proteins between two (or more) samples is quantitative proteomics. A typical technique for this type of proteomics has been two-dimensional gel electrophoresis, in which proteins are separated by their isoelectric points (pIs) and molecular weights, after which the proteins of interest are identified by mass spectrometry (MS). However, gel-based approaches have disadvantages, including the amount of materials required, their reproducibility, and the limit in sensitivity due to protein loss. These are in contrast to recent advances in protein staining that allow intragel comparison of protein quantity between the two or three samples using DIGE. ${ }^{1,2}$

Another enabling approach for proteomics analysis is liquid chromatography mass spectrometry (LC-MS). LC-MS allows increased sensitivity compared to gel-based approaches. ${ }^{3,4}$ There are label-free and label-assisted methods in the relative quantification of proteins using LC-MS. In the label-free method, peptides from digested proteins are compared through their MS intensity or by the number of peaks in the MS/MS spectra. Quantification, by analyzing two samples in parallel and

*Reprint requests to Dr. Jong Shin Yoo

E-mail: jongshin@kbsi.re.kr comparing the shapes of the mass spectra is not straightforward. Isotopic labeling of peptides allows two samples to be analyzed in a single experiment. Isotope-coded affinity tagging, using ICAT reagent technology, yields the peak heights as a measure of relative quantity in the peptide source. ${ }^{1}$ However, comparing the ICAT reagent approach with two-dimensional gel electrophoresis shows that neither method offers complete coverage of a proteome. Commonly used labeling techniques include, for example, chemical labeling ( $\mathrm{ICAT}^{5}{ }^{18}{ }^{18} \mathrm{O}$-labeling ${ }^{6}$ ) and metabolic labeling (SILAC). These methods are generally limited to two-plex protein quantification. Recently, iTRAQ (isobaric tags for relative and absolute quantitation) labeling reagents have been developed which can overcome some of the limitations described above. ${ }^{5}$

iTRAQ reagents enable up to four samples to be analyzed within the same experiment. iTRAQ is reactive toward primary amine groups of peptides, produced by tryptic digests, and isobaric, with a differential set of isotopes distributed between the reporter and balance groups. Tagging of primary amine groups allows the labeling of virtually all peptides in a mixture, unless both lysine and reactive $\mathrm{N}$-terminus are lacking. This provides an advantage over the isotope-coded affinity tag (ICAT) method, which relies on cysteine-specific labeling, subsequently leading to a bias toward cysteine-rich peptides, while iTRAQ tagging presents the intensity of the product reporter ion 
and shows the MS intensity of labeled peptides including cysteine resulting from tandem mass spectrometric analysis of the isobarically tagged peptides. Using the iTRAQ method, we performed two-dimensional LC (2D-LC) of labeled peptides prior to MS/MS analysis to allow for extensive separation of the peptide fragments, thereby identifying more peptides giving qualitative information; this is a standard method in proteomics. The protein can be identified and quantified by more peptides, thus enhancing the levels of confidence in protein quantification. ${ }^{7-9}$

In the present study, we looked into glutamate-induced oxidative injury, which causes the neuronal degeneration related to many central nervous system diseases, such as Parkinson's disease, Alzheimer's disease, epilepsy, and ischemi.a ${ }^{10-13}$ Using iTRAQ, followed by 2D-LC-MS/MS, as an initial screening tool to determine the proteins of interest, we examined proteins that were differentially expressed between three cell types. We investigated the differential proteome in several stroke time pathways: 0,4 , and $8 \mathrm{~h}$. This was followed by glutamate oxidant stress for mouse neuronal cells. ${ }^{11,12}$ Using iTRAQ, we were able to identify both up-regulated and down-regulated proteins for the stroke time pathways.

\section{Experimental Section}

\section{Cell culture and sample preparation}

Mouse HT22 cells were grown in subconfluent cultures in Dulbecco's modified Eagle's medium (DMEM), supplemented with $10 \%$ fetal bovine serum (Atlantic Biological, Norcross, GA). Samples were maintained in a $5 \% \mathrm{CO}_{2}$ humidified atmosphere at $37^{\circ} \mathrm{C}$. Cells $\left(5 \times 10^{5}\right)$, were incubated for $24 \mathrm{~h}$, and then exposed to $5 \mathrm{mM}$ glutamate for apoptosis. Cells were harvested at 0,4 , and $8 \mathrm{~h}$ after glutamate exposure and homogenized in an isotonic homogenization buffer, containing $10 \mathrm{mM}$ Tris- $\mathrm{HCl}$ at $\mathrm{pH} 7.4,250 \mathrm{mM}$ sucrose, $10 \mathrm{mM} \mathrm{KCl}$, $1.5 \mathrm{mM} \mathrm{MgCl}$, $1 \mathrm{mM}$ EDTA, $1 \mathrm{mM}$ DTT, $0.2 \mathrm{mM}$ PMSF, $1 \mathrm{mg} / \mathrm{mL}$ Pepstain A, and $1 \mathrm{mg} / \mathrm{mL}$ Leupeptin using a Dounce homogenizer. Lysates were centrifuged at 8,000 $\times \mathrm{g}$ for $10 \mathrm{~min}$; this resulted in a supernatant and pellet. The pellet was precipitated with acetone and dried.

\section{Trypsin digestion and iTRAQ labeling}

Dried proteins from each cell line were dissolved in $20 \mathrm{uL}$ $500 \mathrm{mM}$ triethyl ammonium bicarbonate (TEAB) dissolution buffer and $1 \mathrm{uL}$ denaturant. The samples were chemically reduced and alkylated using $2 \mathrm{uL}$ reducing reagent and $1 \mathrm{uL}$ cysteine blocking reagent, as described and supplied in the iTRAQ kit (Applied Biosystems iTRAQ ${ }^{\mathrm{TM}}$ Reagents). A vial of trypsin in $25 \mathrm{uL}$ Milli-Q Water was added to each sample and the trypsin digestion was carried out at $37{ }^{\circ} \mathrm{C}$ overnight, according to the standard protocol supplied by the manufacturer. Normoxic cell lysates were labeled with iTRAQ reagents 116 and $117(0 \mathrm{~h})$ and hypoxic cell lysates were labeled with iTRAQ reagents $114(8 \mathrm{~h})$ and $115(4 \mathrm{~h})$. Each labeled digest was then combined into one sample and dried in vacuum.

\section{D LC-MALDI-MS/MS analysis}

The LC-MS/MS was performed by a MALDI-TOF/TOF spectrometer (4700 Proteomics Analyzer, Applied Biosystems, Framingham, MA) equipped with an integrated Famos autosampler, Switchos switching pump, and Probot MALDI spotting device (LC packings, Amsterdam) with SCX/RP columns as descried in Choi, et al. ${ }^{13}$ (2009). Every fraction was collected at $10 \mathrm{~s}$ intervals directly onto 6 wells in a 576 well MALDI plate, and $5 \mathrm{mg} / \mathrm{mL}$ of $\alpha$-cyano-4-hydroxycinnamic acid (CHCA) in 70\% ACN/0.1\% TFA was added by a Probot MALDI spotting device. Mass spectra were obtained using a Nd:YAG laser $(355 \mathrm{~nm}, 200 \mathrm{~Hz})$.

\section{Database search and statistical analysis}

A database search for the iTRAQ experiments was performed with GPS software (Version 3.6, Applied Biosystems) to identify and quantify the raw MS/MS data from the MALDI-TOF/TOF mass spectrometer. For protein identification, the MS/MS data were analyzed using the NCBI database (Version 3.40) with the MASCOT search engine (Version 1.9, http://www. matrixscience.com). We converted the peak area values of the identified peptides to their $\log 2$ value and normalized them with a MA plot. We also calculated the distribution of peptides with $\log 2114 / 117,115 / 117$, and 116/117. For data integration, we applied category analysis. The threshold for protein identification was set at $>95 \%$ confidence level.

\section{Results and Discussion}

We examined proteins from one control cell line and three different stage cell lines. These four samples of peptide mixtures were labeled with 4-plex iTRAQ reagents and separated by using 2D LC-MS/MS to identify the relative quantities of the peptides from four samples. In fact, we analyzed the differential proteomes in three stroke time pathways $(0,4$, and $8 \mathrm{~h})$, after glutamate oxidant stress of mouse neuronal cells. The control sample treated with glutamate at $0 \mathrm{~h}$ was labeled with a 116 iTRAQ reagent and that without glutamate treatment was labeled with a 117 iTRAQ reagent. The sample treated with glutamate was labeled using two iTRAQ reagents $114(8 \mathrm{~h})$ and 115 ( $4 \mathrm{~h}$ ) 115 and 114 at 4 and 8 h, respectively, as shown in Figure 1. In the first step, we filtered out the data providing the $116 / 117$ ratio other than $1: 1$ and identified the chemically labeled peptides in each cell line. In the next step, the peptides identified with low confidence-were removed. In the final step, the normalized ratios were obtained by weighing iTRAQ peptides according to their peak intensities to calculate the average protein ratios.

In this experiment, the ratios of grouped proteins from one set of experiments are plotted in Figure 2, which shows the distribution of the 116/117 ratio from mouse neuronal cell line proteins, which presents the $p$-value $<0.05$. Analyzing the statistical distribution of the peptide ratios obtained for each plot, we find the ratio of around 1:1 from every group. Nevertheless, $\log (114 / 117)$ and $\log (115 / 117)$ values are 

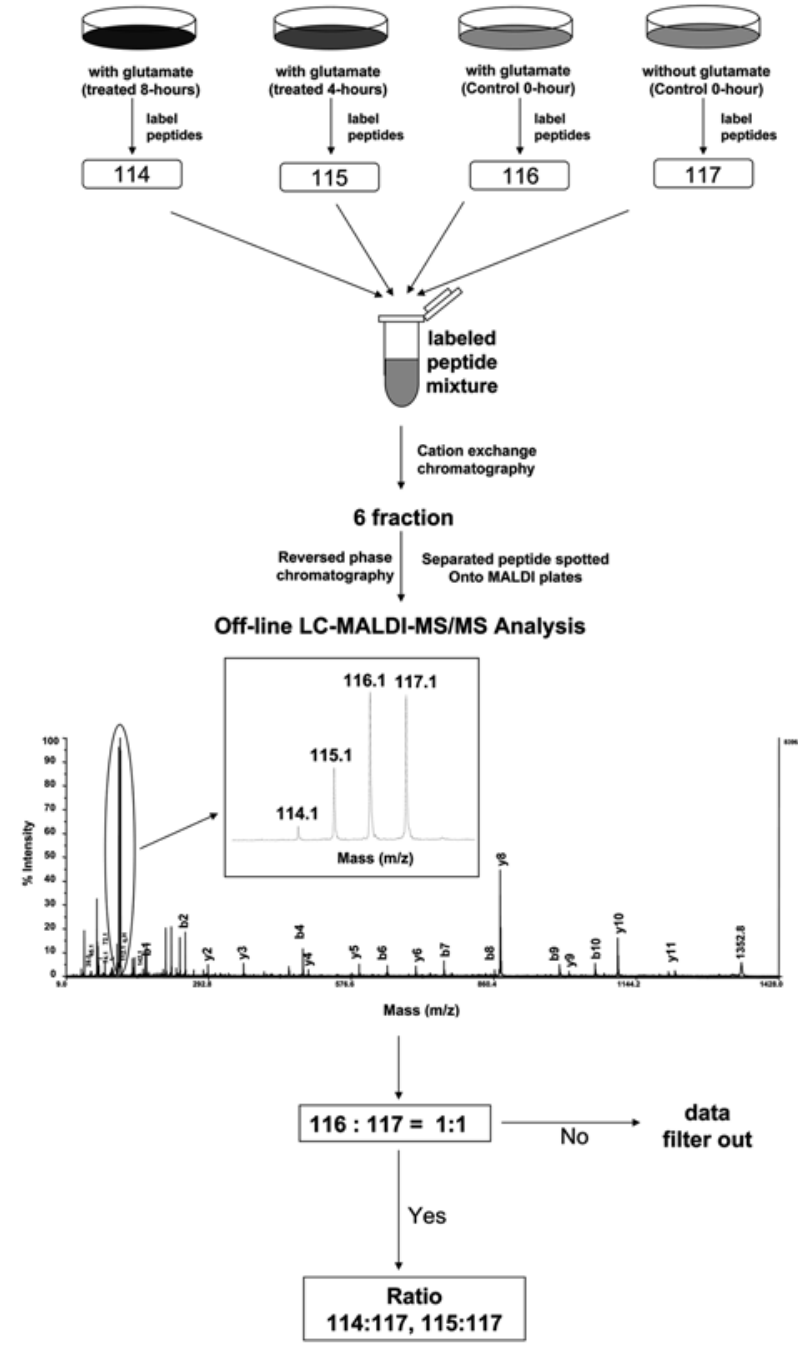

Figure 1. Experimental workflow. The proteins from control cells as well as cells treated with glutamate oxidative stress for stroke times of 0,4 , and $8 \mathrm{~h}$.

shifted a little bit downward and upward, respectively. The $\log$ ratio distribution is plotted in Figure 2B and fitted to a Gaussian distribution. The $95 \%$ confidence ratio ranges from 0.287 to 1.478 . This statistical analysis allows evaluation of the normalized ratios, as shown in Figure 3. For high-throughput quantitative proteomics, a normal distribution should be chosen to minimize the effect of peptides with low signal-to-noise $(\mathrm{S} / \mathrm{N})$ ratios on the normalization process. After removing the ratios of peptides which are saturated or have low S/N ratios, iTRAQ peptides are weighted according to their peak intensities to calculate the average protein ratios. Of the 214 proteins identified from the present protein quantification experiments, we find 8 up-regulated and 4 down-regulated proteins for the stroke time pathways (see Table 1 and Supplementary Figure 1).

Among up-regulated proteins, we find histones, such as $\mathrm{H} 2 \mathrm{~A}$, $\mathrm{H} 2 \mathrm{~B}, \mathrm{H} 3, \mathrm{H} 4$, which are normally organized into nucleosomes and histone $\mathrm{H} 1$ is located on the internucleosomal DNA in

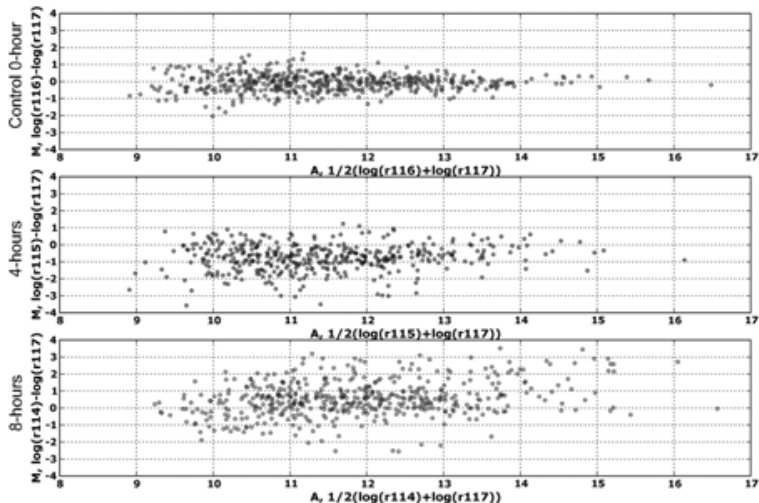

(A)

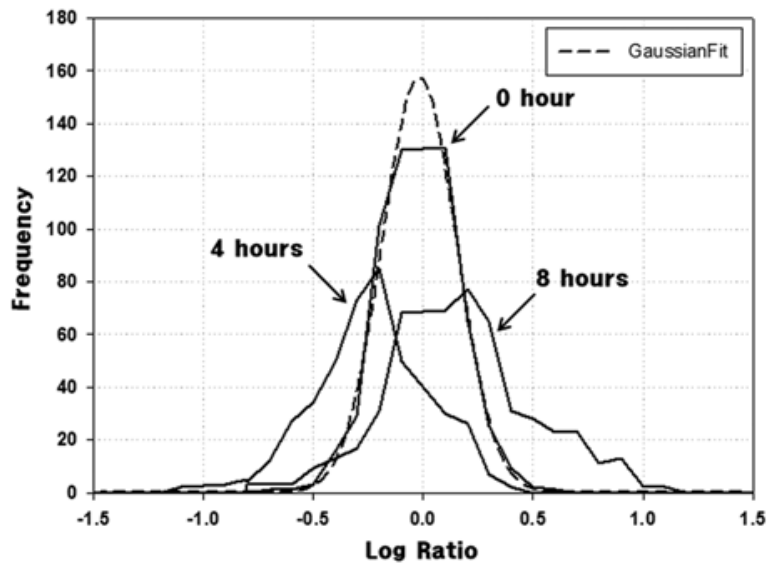

(B)

Figure 2. (A) The scatter plot and (B) the distribution of each of the differential control peptides by an iTRAQ peak ratios $\log (116 / 117)$ (with and without glutamate treated at $0 \mathrm{~h}$ ), $\log (115 / 117)$ (with glutamate treated at $4 \mathrm{~h}), \log (114 / 117)$ (with glutamate at $8 \mathrm{~h}$ ).

mammalian cells. They are released from the nucleus during apoptosis and then exposed on the surface of apoptotic cells. The eukaryotic elongation factor $1 \mathrm{~A}(\mathrm{eEF} 1 \mathrm{~A})$ is an important member of the G-protein family and represents an essential component during protein synthesis by binding aminoacyl-tRNAs in a GTP-dependent reaction to the acceptor site of ribosomes during peptide chain elongation. Among down-regulated proteins, we find heterogeneous nuclear ribonucleoproteins (hnRNPs) A1 and A2/B1 that have some common functions, with both being implicated in telomere maintenance and regulation of cell proliferation. ${ }^{14-17}$

\section{Conclusions}

We utilized iTRAQ to analyze the differential proteome in three stroke time pathways by treating the mouse neuronal cell samples with glutamate oxidant stress. We identified 214 proteins using a normalization of control 116/117 for the glutamate treatment. We also found 8 up-regulated and 4 downregulated proteins for the stroke time pathways. The present 
Table 1. Up- and down-regulated proteins by time pathways

\begin{tabular}{|c|c|c|c|c|c|c|}
\hline \multicolumn{7}{|c|}{ Up-reglurated Proteins } \\
\hline No. & Annotation & Protein name & $\begin{array}{c}\text { Average ratio } \\
\log 116 / 117(0-h)\end{array}$ & $\begin{array}{c}\text { Average ratio } \\
\log 116 / 117(4-h)\end{array}$ & $\begin{array}{c}\text { Average ratio } \\
\log 116 / 117(8-h)\end{array}$ & $\begin{array}{l}\text { Number } \\
\text { of peptide }\end{array}$ \\
\hline 1 & gil13430890 & Histone $1, \mathrm{H} 1 \mathrm{c}$ & $-0.2( \pm 0.11)$ & $-0.24( \pm 0.13)$ & $0.481( \pm 0.14)$ & 3 \\
\hline 2 & gil55977057 & Histone H3.1 & $0.04( \pm 0.11)$ & $-0.12( \pm 0.22)$ & $0.63( \pm 0.29)$ & 3 \\
\hline 3 & gil31543315 & Nucleolin & $-0.03( \pm 0.15)$ & $-0.08( \pm 0.16)$ & $1.11( \pm 0.19)$ & 2 \\
\hline 4 & gil56237861 & OTTMUSP00000000551 & $0.1( \pm 0.16)$ & $-0.01( \pm 0.08)$ & $0.76( \pm 0.08)$ & 2 \\
\hline 5 & gil56237956 & RP23-9016.12 & $-0.03( \pm 0.04)$ & $0.02( \pm 0.16)$ & $0.64( \pm 0.16)$ & 5 \\
\hline 6 & gil51767569 & similar to Gist $1 \mathrm{~h} 2 \mathrm{bc}$ protein & $-0.07( \pm 0.02)$ & $-0.06( \pm 0.03)$ & $0.75( \pm 0.07)$ & 2 \\
\hline 7 & gil51712540 & similar to Zgc: 56193 & $0.02( \pm 0.16)$ & $-0.11( \pm 0.09)$ & $0.59( \pm 0.09)$ & 7 \\
\hline 8 & gil26345494 & Unnamed protein product & $0.08( \pm 0.03)$ & $-0.32( \pm 0.03)$ & $0.76( \pm 0.1)$ & 2 \\
\hline \multicolumn{7}{|c|}{ Down-reglurated Proteins } \\
\hline No. & Annotation & Protein name & $\begin{array}{c}\text { Average ratio } \\
\log 116 / 117(0-h)\end{array}$ & $\begin{array}{c}\text { Average ratio } \\
\log 116 / 117(4-h)\end{array}$ & $\begin{array}{c}\text { Average ratio } \\
\log 116 / 117(8-h)\end{array}$ & $\begin{array}{l}\text { Number } \\
\text { of peptide }\end{array}$ \\
\hline 1 & gil6752954 & Actin, gamma, cytoplasmic 1 & $-0.01( \pm 0.18)$ & $-2.05( \pm 0.67)$ & $-1.2( \pm 0.55)$ & 13 \\
\hline 2 & gil6754222 & Heterogeous nuclearribonucleoprotein A/B & $-0.01( \pm 0.09)$ & $-0.16( \pm 0.11)$ & $-0.33( \pm 0.32)$ & 9 \\
\hline 3 & gil2596545 & Envelope glycoprotein 1 & $-0.01( \pm 0.18)$ & $-2.03( \pm 0.56)$ & $-0.8( \pm 0.48)$ & 11 \\
\hline 4 & gil34784211 & endo-1, 3-beta-glucosidase & $-0.01( \pm 0.28)$ & $-2.03( \pm 0.34)$ & $-1.87( \pm 0.57)$ & 2 \\
\hline
\end{tabular}

results suggest that histone $\mathrm{H} 1 \mathrm{might}$ be the key protein in the oxidative injury caused by glutamate-induced cytotoxicity in HT22 cells. ${ }^{15-19}$

\section{Acknowledgments}

This work was supported by the Korea Basic Science Institute Grant G30121 and the Ministry of Education, Science and Technology (2009-008146). The authors are greatly thankful to Dr. Sung Hyun Kang at Korea Research Institute of Bioscience \& Biotechnology and Dr. Sung Eun Ryu at Hanyang University.

\section{References}

1. Gygi, S. P; Rist, B.; Gerber, S. A.; Turecek, G.; Gelb, M. H.; Aebersold, R. Nat, Biotechnol. 1999, 17, 994.

2. Wilm, M.; Shevchenko, A.; Houthaeve, T.; Breit, S.; Schweigerer, L.; Fotsis, T.; Mann, M. Nature. 1996, 379, 466.

3. Link, A. J.; Hays, L. G.; Carmack, E. B.; Yates, J. R. Electrophoresis 1997, 18, 1314.

4. Sachon, E.; Mohammed, S.; Bache, N.; Jensen, O. N. Rapid Commun. Mass Spectrom. 2006. 20, 1127.

5. Gygi, S. P.; Rochon, Y.; Franza, B. R.; Aebersold, R. Mol. Cell. Biol. 1999, 19, 1720.

6. Desiderio, D. M.; Kai, M. Biomed. Mass Spectrom. 1983, $10,471$.

7. Richard, D. U.; Andrew, P.; Rod, B. W.; David, W. S.; Anthony, D. W. Mol. Cell Proteomics 2005, 4, 924.

8. Philip, L. R.; Yulin, N. H.; Jason, N. M.; Brian, W.; Kenneth, P.;
Stephen, H.; Nikita, K.; Sasi, P.; Subhakar, D.; Scott D.; Subhasish, P.; Peter, J.; Stephen, M.; Michael, B. J.; Feng, H.; Allan, J.; Darry, J. P. Mol. Cell. Proteomics. 2004, 3, 1154.

9. Wells, W. W.; Guanghui, W.; Seung, J. B.; Rong, F. S. J. Proteome Res. 2006, 5, 651.

10. Jeong, G. S; Byun, E.; Li, B.; Lee, D. S.; An, R. B.; Kim, Y. C. Arch. Pharm. Res. 2010, 33(8), 1269.

11. Lin, W. T.; Hung, W. N.; Yian, Y. H.; Wu, K. P.; Han, C. L.; Chen, Y. R.; Chen, Y. J.; Sung, T. Y.; Hsu, W. L. J. Proteome Res. 2006, 5, 2328.

12. Claire, R.; Anne, G. P.; Cecile, D.; Maighread, G.; Jerome, G. Mol. Cell. Proteomics 2006, 5, 68.

13. Choi, S. K.; Cho, K.; Kim, J. Y.; Yea, K. M.; Park, G. W.; Lee, J. H.; Ryu, S. H.; Kim, J.K ; Kim, Y. H. Biochemical and Biophysical Research Comunucations 2009, 383, 135.

14. Bond, C. E.; Patel, P.; Crouch, L.; Tetlow, N; Day, T.; Abu, H. S.; Williamson, C.; Greenfield, S. A. Eur. J. Neurosci. 2006, 24(2), 381.

15. Han, S. P.; Tang, Y. H.; Smith, R. Biochem. J. 2010, 430, 379.

16. Gygi, S. P.; Han, D. K.; Gingras, A. C.; Sonenberg, N.; Aebersold, R. Electrophoresis 1999, 20(2), 310.

17. Jeremy, E. M.; Kenneth, A. C.; Devanand, M. P. Rapid Commun. Mass Spectrom. 2006. 20, 904.

18. Wang, K.; Pruthodam, S.; Lee, J. Y.; Na, M. H.; Park, H.; Oh, S. J.; Park, R. W.; Park, J. Y.; Lee, E. B.; Cho, B. C.; Song, M. N.; Baek, M. C.; Kwak, W. J.; Yoo, J. S.; Hoffman, A. S.; Oh, Y. K.; Kim, I. S.; Lee, B. H. Journal of Controlled Release 2010, 09, 10.

19. Ha, J. S; Lim, H. M.; Park, S. S. Brain Research 2010, $1359,291$. 